\title{
Assured Rewards Facilitate Non-Intervention in Unfair Situations by High Psychopathy Individuals
}

\author{
Keita Masui ${ }^{1,2}$, Shouichi Iriguchi ${ }^{3} \&{\text { Mitsuhiro } \text { Ura }^{3}}^{3}$ \\ ${ }^{1}$ Research Fellow of the Japan Society for the Promotion of Science, Japan \\ ${ }^{2}$ Department of Psychology, Keio University, Japan \\ ${ }^{3}$ Graduate School of Integrated Arts and Science, Hiroshima University, Japan \\ Correspondence: Keita Masui, Keio University Higashi-Bekkan 117, 2-14-6, Mita, Minato-ku, Tokyo, 108-8345, \\ Japan. Tel: 81-80-5754-9316. E-mail: kmasuii@gmail.com
}

Received: June 30, 2014

doi:10.5539/ijps.v6n4p56
Accepted: August 24, $2014 \quad$ Online Published: November 10, 2014

URL: http://dx.doi.org/10.5539/ijps.v6n4p56

\begin{abstract}
Although third-party punishment plays a crucial role in the maintenance of reciprocal cooperative relationships in human society, for various reasons such punishment is not consistently levied even when it may be appropriate to do so. The present study investigated the effects of external incentives and psychopathy on non-intervention in a situation where third-party punishment would be warranted. Forty participants who completed a measure to assess psychopathy participated in an experiment in which they had to choose either to punish social norm violators as third-parties, to help victims, or to refrain from correcting the unfair outcomes, under conditions where non-intervention was either rewarded or punished. Results showed that frequency of non-intervention decreased in a condition where there were assured punishments with non-intervention, with participants more likely to intervene in the unfair situation as a third-party. On the other hand, frequency of non-intervention increased when there was assured rewards for non-intervention, with many participants failing to correct the unfair outcomes. Additionally, this tendency was accentuated in high psychopathy individuals. The implications of these results for future research on the cultivation and continuation of reciprocal human relationship is discussed.
\end{abstract}

Keywords: intervention, altruistic behavior, psychopathy, incentive

\section{Introduction}

\subsection{Altruism, Intervention, and Non-Intervention}

Altruism is a unique feature of human beings, and altruistic behavior is one of the key essential factors that maintains reciprocal cooperative relationships in human society, working to reduce the amount of unjust behavior that occurs. When we encounter an unfair economic exchange situation between others, we are often willing to punish people who have violated the social norm of reciprocity and seek to correct the unfair outcome, even in situations in which we are not directly involved and the exchange between others does not directly affect our degree of economic payoff (Fehr \& Fischbacher, 2004a). In addition, such third-party punishment occurs even in situations where such actions are personally costly. Third-party punishment behavior can be observed across diverse human societies, and appears to have a role in reducing the amount of unjust behavior that occurs within groups (e.g., Fehr \& Gächter, 2002).

People may be motivated to engage in third-party punishment for a variety of reasons. One potential reason is that human society is based on social norms, with people behaving in accordance with such norms in order to ensure smooth societal functioning. Previous research has found that third-party punishment is driven by negative emotions and negative fairness judgments towards norm violators (Fehr \& Fischbacher, 2004a). Moreover, Fehr and Fischbacher (2004b) reviewed evidence showing that non-selfish motivation for punishment constitutes an important factor for the enforcement of social norms and human cooperation, and that norm enforcement affects the frequency of third-party punishment.

Another potential motivator of third-party punishment is that people could gain personal rewards for engaging in such behavior, including feelings of satisfaction or joy. For example, de Quervain et al. (2004) found that activation of the dorsal striatum, a central component of the brain's reward system, increases when participants 
punish norm violators when doing so is costly. Additionally, the degree of this activation is positively correlated with the amount of third-party punishment administered.

Despite a possible link between third-party punishment and non-selfish motivation, such punishment is not consistently carried out. In a previous study, roughly $40 \%$ of third-party participants did not punish the unfair proposer in the dictator game, which has been widely used to assess economic decision-making in the laboratory (Fehr \& Fischbacher, 2004a). In the dictator game, two players (the proposer and the receiver) are given an opportunity to split a sum of money. The proposer offers a portion of the money to the receiver and keeps the remainder for him or herself. The receiver does not have a chance to reject and just has to accept the proposer's offer even if the offer is unfair. In another study, participants as third-parties were given an opportunity to punish unfair proposers by using their endowments. About half of the participants never intervened in the unfair situations (Leibbrandt \& López-Pérez, 2011). Clearly it is not uncommon to choose not to intervene in such situations. Nevertheless, the relationship between non-intervention in unfair situations and various external and internal mediating factors remains poorly understood.

\subsection{Relationship between Non-Intervention in Unfair Situations and Incentives as an External Factor}

In this study, we focus on incentives as an external factor likely to play an important role in non-intervention in unfair situations involving other parties. It is well-known that rewards serve as positive reinforcement to increase the frequency of a behavioral response, while punishments serve to decrease such frequencies (Skinner, 1938). The incentive theory of motivation suggests that people are motivated to engage in behavior in order to gain rewards, with a corresponding tendency to avoid behaviors associated with punishments (Bernstein, 2011). From this perspective, individuals should be more likely to engage in non-intervention when there are clear rewards for doing so. On the other hand, punishments for non-intervention should work to increase the likelihood of intervention in the form of third-party punishment.

\subsection{Relationship between Non-Intervention in Unfair Situations and Psychopathy as an Internal Factor}

The present study also investigated the effect of a specific personality trait as an internal factor on non-intervention in unfair situations involving others. Researchers have tried to clarify what personality traits are associated with selfishness and a lack of altruism or empathy, with psychopathy being one of the most studied (Masui, Iriguchi, Nomura, \& Ura, 2011; Rilling et al., 2007). Psychopathy is a personality trait characterized by egocentricity, irresponsibility, shallow emotions, callousness, lack of empathy or guilty, pathological lying, manipulativeness, impulsivity, and "the persistent violation of social norms and expectations" (Hare, 1998, pp. 188). Psychopathy has been traditionally conceptualized with reference to clinical or criminal populations. However, taxometric studies have indicated that psychopathy is a dimensional construct ranging in severity from clinical to non-clinical levels, whether assessed by self-report (Marcus, John, \& Edens, 2004) or via clinical ratings using the Psychopathy Checklist-Revised (PCL-R; Edens, Marcus, Lilienfeld, \& Poythress, 2006; Guay, Ruscio, Knight, \& Hare, 2007; Hare, 1991, 2003). Some studies have assessed individual differences in psychopathy within general populations and found results similar to studies conducted with incarcerated populations, where the base rate of psychopathy is considerably higher. Within community samples, higher levels of psychopathy have been shown to be associated with increased immoral behavior, even if the individuals have never been convicted of a crime (Belmore \& Quinsey, 1994; Ishikawa, Raine, Lencz, Bihrle, \& Lacasse, 2001).

Deficits in altruistic emotion, empathy and sympathy are thought to foundational to the concept of psychopathy. Various studies have identified such affective and emotional characteristics in high psychopathy individuals from both clinical and non-clinical samples (e.g., Koenigs, Krueple, \& Newman, 2010; Masui et al., 2011). For example, Koenigs et al. (2010) examined the relationship between psychopathy and the frequency of unfair offers in the dictator game, using a sample of institutionalized individuals. Koenigs et al. (2010) found that high psychopathy individuals proposed more unfair offers during this game as compared to low psychopathy individuals. Moreover, high psychopathy individuals are more likely to betray their partners during the prisoner's dilemma game, which assesses relationships based on reciprocal altruism, defined as the reciprocal exchange of favors (Rilling et al., 2007). In regard to the relationship between costly punishment behavior and psychopathy in general populations, Masui et al. (2011) found that high psychopathy individuals administered costly punishments to transgressors not for altruistic reasons but to increase subjective emotional gratification. Findings of abnormal face perception ability in high psychopathy individuals are similarly consistent with a relative lack of empathy or sympathy. For example, high psychopathy participants show more diminished physiological responses to various aversive facial stimuli, such as sad or angry faces, compared to those with low psychopathy (e. g., Birbaumer et al., 2005; Flor, Birbaumer, Hermann, Ziegler, \& Patrick, 2002; Levenson, 
Patrick, Bradley, Lang, 2000). The finding that high psychopathy individuals display less empathy relative to their low psychopathy peers suggests the possibility that psychopathy would affect the frequency of non-intervention in unfair situations involving other parties.

It has also been determined that external incentives facilitate the expression of psychopathic characteristics in individuals high in this trait (e.g., Masui \& Nomura, 2011). Masui and Nomura (2011) examined the effects of degree of reward and punishment on response inhibition in high and low psychopathy participants. They found that low psychopathy participants showed improved response inhibition under reward and punishment conditions, as compared to a no incentive condition. In contrast, high psychopathy participants showed response inhibition deficits under high incentive conditions. These findings indicated that while low psychopathy individuals more carefully select their behaviors in the presence of rewards and punishments, high psychopathy individuals often fail to alter their behaviors, regardless of reward and punishment contingencies. Some questionnaire research has also identified a significant positive association between psychopathy and reward sensitivity (e.g., Newman, MacCoon, Vaughn, \& Sadeh, 2005; Osumi, Kanayama, Sugiura, \& Ohira, 2007). Based on the finding that high psychopathy individuals show hypersensitivity to rewards, it is possible that when non-intervention in an unfair third-party situation is associated with reward, such individuals would be likely to fail to intervene in order to reap the benefits.

\subsection{Experimental Paradigm to Assess Intervention and Non-Intervention}

The present study uses the intervention paradigm, which is a variant of the third-party punishment paradigm. Fehr and Fischbacher (2004a) designed the third-party punishment paradigm by incorporating aspects of the dictator and prisoner's dilemma games. In the third-party punishment paradigm, three players are assigned to the proposer, receiver, and third-party roles. This paradigm consists of two phases. In the first phase, the proposer unilaterally decides the distribution ratio of a certain amount of money with the receiver. The receiver does not have a chance to deny the offer of the proposer, as per the dictator game. The third-party observes the actions of the other two players. In the second phase, the third-party is given an opportunity to punish proposers by using their endowments, such that punishment is in fact costly for the third-party. Fehr and Fischbacher (2004b) argued that the third- party punishment paradigm provides a robust assessment of the willingness to punish social norm violators, given that the other players' actions do not directly affect the third party's economic payoff in any way.

Fehr and Fischbacher (2004a) argued that a selfish third-party would be quite unlikely to punish a third-party in this paradigm, given the cost involved. However, it remains possible that a reluctance to inflict emotional or physical pain on others prevents individuals from inflicting third-party punishment, even if participants do empathize with the victims of an unfair deal. To eliminate this possibility, the present study added an additional third-party response option, that of "helping victims" (along with the more typical options of third-party punishment and non-intervention). This approach should permit differentiation of motives for non-intervention, as altruistic non-punishers who hesitate to punish the proposer would be likely to choose the option of helping the receiver, leaving non-intervention as an option for those individuals who would refrain from third-party punishment for other reasons (e.g., obtaining a reward for failing to intervene). Reward and punishment for non-intervention were manipulated in order to examine the relationship between the three intervention options and external incentives.

\subsection{The Present Study}

The purpose of this study was to use the intervention paradigm to examine the relationship between non-intervention in an unfair situation, external incentives, and psychopathy. Based on previous findings regarding the effect of external incentives on motivation in psychopathy, we hypothesized that non-intervention in the unfair situation would be increased under the condition in which there were rewards associated with non-intervention, as compared to punishments for this behaviour. Moreover, because psychopathy is positively associated with hypersensitivity to rewards, high-psychopathy participants should be less likely to intervene than low psychopathy ones, particularly when non-intervention is rewarded.

\section{Method}

\subsection{Participants}

Forty university students (23 females) who completed the Japanese version of the Levenson Self-Report Psychopathy (LSRP) scale were recruited in an introductory psychology class. They individually participated in the laboratory experiment about one week after completing the LSRP scale. All participants took part in the present study in exchange for partial course credit. 
Participants were divided into high psychopathy $(n=21)$ and low psychopathy groups $(n=19)$ on the basis of a median split of total LSRP scores. A similar approach has been used in prior studies to facilitate within- and between-group analyses (e.g., Masui, et al., 2012; Masui \& Nomura, 2011). Mean ages were 18.62 for the high psychopathy group $(S D=0.67$, age range $=18-20$ years $)$ and 18.68 for the low psychopathy group $(S D=0.67$, age range $=18-20$ years $)$. There was no significant difference between mean ages $(t(38)=0.31, p=.76, d=$ 0.09).

Prior to completing the LSRP scale, the experimenter briefed participants about the nature of the present study, and participants were also given a written description. Those willing to take part in the study were asked to sign and return a consent form. After signed consent was obtained, participants completed the LSRP scale on their own, in a paper-and-pencil format. A researcher collected the questionnaire immediately after participants responded.

The Ethics and Safety Committee of Hiroshima University approved the study protocol.

\subsection{Overview of Procedures}

The present study used the intervention paradigm. One participant per testing session arrived at the laboratory and was seated in front of a desktop computer. All participants were told that this study was examining economic decision-making, and that they would be playing a money distribution game on the computer against two human players (in reality, all participants were playing against the computer). To ensure that the participants believed they were playing against other people, we communicated with a collaborator via a wireless transceiver, as if to suggest that other participants were playing the game at the same time but in a different laboratory.

The intervention paradigm consists of two phases. In the first phase, two computer "players" distributed 2000 yen (about 20 US dollars). At that time, one "player", the proposer, decided the ratio of distribution from two options on the screen. Two options were randomly selected from four distribution ratios, such that all options were selected equally often across trials (8:2, 7:3, 6:4, and 5:5). The proposer chose one option from four distribution ratios at the same rate, and the receiver did not have the option to deny the proposals. After the proposal, the amounts of money acquired by the proposer and receiver were presented on the screen. Participants were all third-parties during this first phase, and they only observed, with no option to intervene.

At the beginning of the second phase, participants received an endowment of 400 yen. During this second phase, participants decided whether or not to intervene in the unfair situations by using their endowments. If participants chose the intervention option, they then decided whether to punish the unfair proposer or help the receiver. Participants then determined to what degree they would punish or help, assigning 100, 200, 300 or 400 yen, such that the proposer lost or the receiver gained three times the money assigned. If participants decided not to intervene in the unfair situations, they could spin a roulette wheel to increase or decrease their money under one of three conditions. In the even condition, two spots on the roulette wheel were assigned as rewards (100 and 150 yen), and two other spots were assigned as punishments (-100 and -150 yen). The expectation was that participants would ultimately gain no money in this condition. The second condition was the reward condition, where all four spots on the roulette wheel were rewards (50, 100, 100, and 150 yen). Participants could obviously increase their net gains in this condition. The third condition was the punishment scenario. In this condition, all four spots on the roulette wheel involved losses (-50, -100, -100, and -150 yen). Roulette was presented in the center of the screen, and the options of third-party punishment, helping, and non-intervention were simultaneously presented beneath the roulette display. Importantly, participants knew the assignment of the four spots before they decided whether or not to intervene in the unfair situations. The three reward/punishment conditions were randomly determined on a per-trial basis, with different random orders being administered to each participant. After that, final monetary gains of the proposer, receiver, and the participant were displayed and the protocol moved on to the next trial. Each participant completed 64 trials.

After completing the intervention paradigm, participants were debriefed and paid 500 yen for their participation.

\subsection{Materials}

The original LSRP scale is a 26-item questionnaire designed by Levenson et al. (1995) to measure psychopathic traits in non-clinical populations; the Japanese version was translated by Sugiura and Sato (2005). The Japanese LSRP scale has adequate test-retest reliability and construct validity (Osumi et al., 2007). Each item is a statement rated on a four-point scale (from disagree strongly to agree strongly).

\subsection{Data Analysis}

We first confirmed that there were indeed robust group differences for LSRP scores. 
To analyse the effects of psychopathy and reward/punishment on participant's degree of intervention, we conducted a mixed model of analysis of variance (ANOVA) with participant group (high psychopathy/low psychopathy) as the between-subjects factor and the participants' choice (punishment/help) ${ }^{1}$ and reward condition (even/reward/punishment) as within-subjects factors. The Bonferroni test was used for post-hoc comparisons.

We then investigated the relationship between non-intervention, external incentives, and psychopathy. We again carried out a mixed model ANOVA that included participant group (high psychopathy/low psychopathy), the participants' choice (punishment/help/non-intervention), and condition (even/reward/punishment).

\section{Results}

\subsection{LSRP Scale Scores}

Average item means for the LSRP scale scores ranged from 2.04 to $2.50(M=2.21, S D=0.13)$ in the high psychopathy group, and from 1.42 to $2.00(M=1.69, S D=0.16)$ in the low psychopathy group. There was a significant group difference between total LSRP scale scores, $t(38)=11.13, p<.001, d=3.59$.

\subsection{Analysis of Amounts of Intervention}

Table 1 shows mean amounts of intervention per trial for high and low psychopathy participants. A mixed-model ANOVA revealed a marginally significant interaction between group, the participants' choice, and condition, $F$ $(2,76)=3.00, p=.06, \eta_{\mathrm{p}}{ }^{2}=.07$. Low psychopathy participants were less likely to help the receiver during the reward condition as compared to the other conditions $(p s<.03)$.

Table 1. Mean amounts of intervention in the unfair situation in high and low psychopathy participants

\begin{tabular}{lllll}
\hline & \multicolumn{2}{l}{ low psychopathy $(n=19)$} & \multicolumn{2}{l}{ high psychopathy $(n=21)$} \\
\cline { 2 - 5 } & $\begin{array}{l}\text { third-party } \\
\text { punishment }\end{array}$ & helping & $\begin{array}{l}\text { third-party } \\
\text { punishment }\end{array}$ & helping \\
\hline even & $166.36(93.40)$ & $168.98(86.46)$ & $176.89(91.08)$ & $179.84(49.57)$ \\
reward & $150.22(117.95)$ & $113.29(94.93)$ & $122.42(110.18)$ & $140.08(96.84)$ \\
punishment & $158.28(84.28)$ & $176.47(57.13)$ & $179.26(107.37)$ & $171.65(57.13)$
\end{tabular}

Note. Numbers enclosed in parentheses express the standard deviations for amount of intervention and number units are yen.

\subsection{Analysis of Frequency of Non-Intervention}

A mixed model ANOVA revealed a significant interaction between participants' choice and condition, $F(4,152)$ $=70.47, p<.001, \eta_{\mathrm{p}}{ }^{2}=.65$ (Figure 1), for the frequency of non-intervention. There was also a significant interaction between group, participants' choice, and condition, $F(4,152)=3.36, p=.01, \eta_{\mathrm{p}}{ }^{2}=.08$ (Figure 2). A post-hoc test showed that non-intervention was more likely than intervention under the reward condition (punishment, $M=2.27, S D=2.27$, helping, $M=3.29, S D=3.37$, non-intervention, $M=9.98, S D=3.85, p$ $<.001)$. On the other hand, participants were more likely to intervene than not under the punishment condition (punishment, $M=6.07, S D=4.05$, helping, $M=8.13, S D=4.07$, non-intervention, $M=1.27, S D=2.05, p$ $<.001$ ). In addition, high psychopathy participants chose the non-intervention option more often than low psychopathy participants under the reward condition (high psychopathy, $M=10.90, S D=3.85$, low psychopathy, $M=8.53, S D=3.29, p=.04)$. 


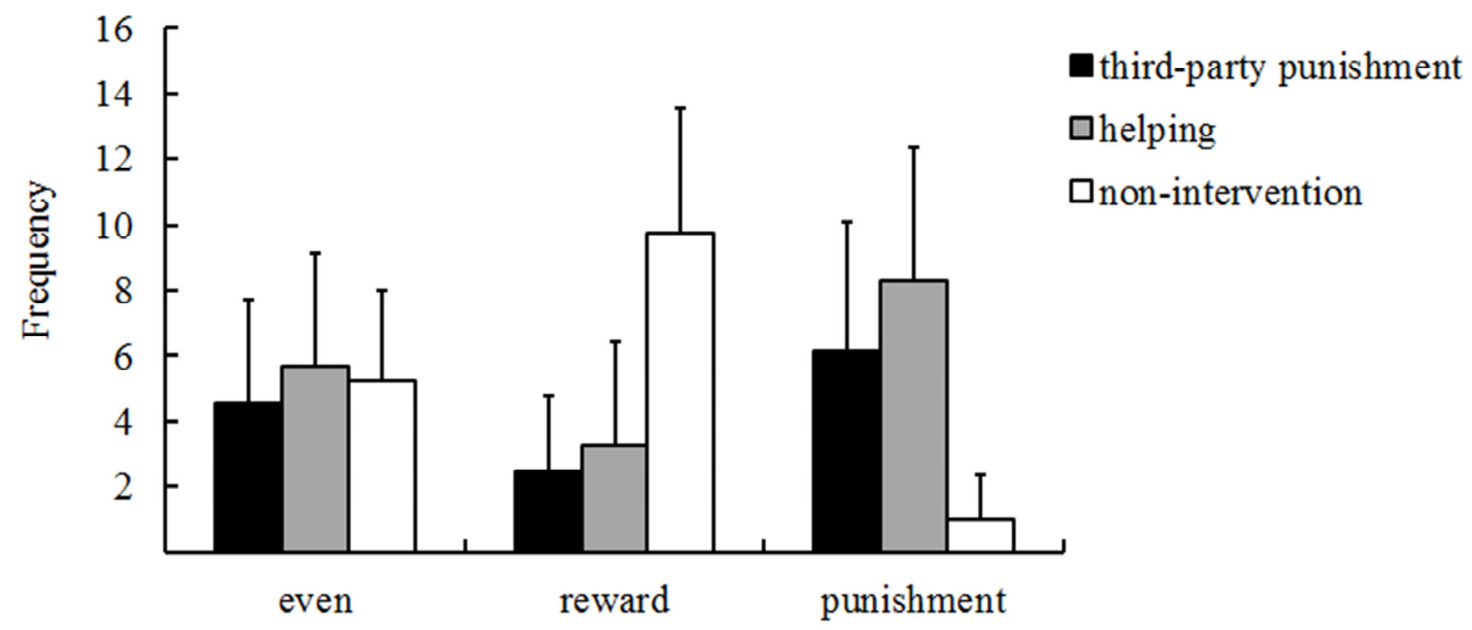

Figure 1. Frequency of intervention and non-intervention under three conditions

Note. Error bars indicate standard deviations.

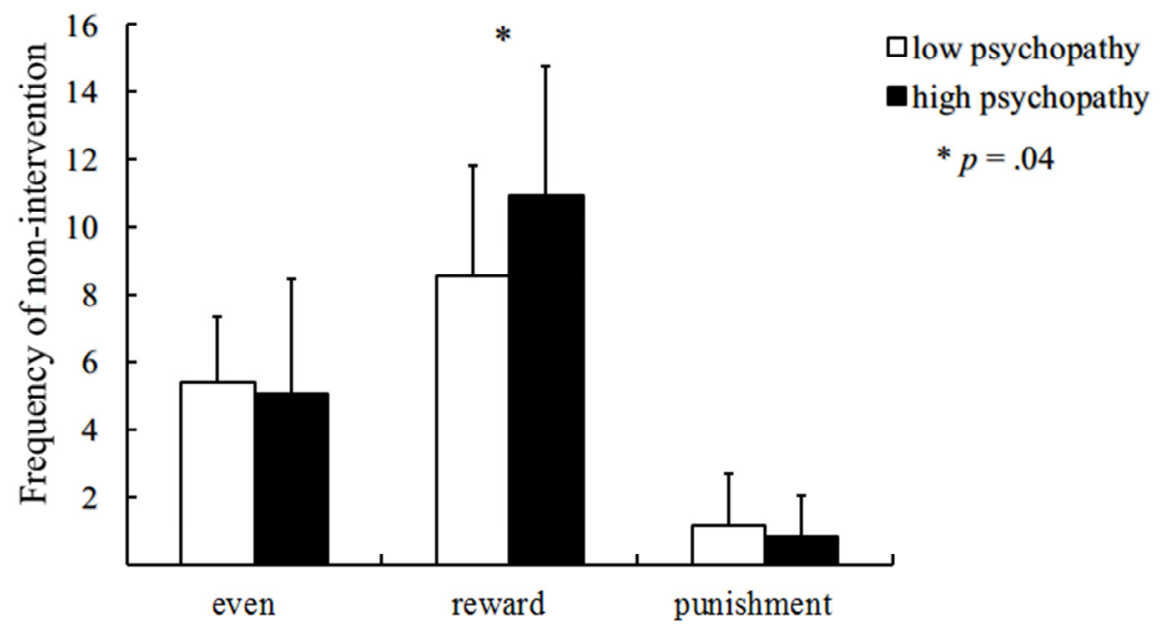

Figure 2. Frequency of non-intervention under the reward condition in high and low psychopathy participants Note. Error bars indicate standard deviations.

\section{Discussion}

The purpose of the present study was to determine the nature of the relationship between non-intervention in unfair situations involving other people, external incentives, and psychopathy.

First, we found that external incentives such as rewards and punishments affected intervention and non-intervention degree and frequency. Results showed that participants were less likely to intervene in an unfair situation and punish the third-party who violated a social norm when there was an opportunity to gain a monetary reward if one failed to intervene, as compared to conditions where the monetary award was not available or non-intervention was actively punished. This result suggests the possibility that assured monetary rewards can play a role as positive reinforcers of non-intervention. Additionally, it is possible that assured punishments could become negative reinforcers of intervention and work to facilitate non-intervention in unfair situations. These findings are consistent with the views of Skinner (1983) and the incentive theory of motivation (Bernstein, 2011).

Secondly, we found that frequency of non-intervention was influenced not just by such external incentives but also psychopathy. Frequency of non-intervention under the reward condition was significantly increased compared to non-reward and punishment conditions regardless of the degree of psychopathy. Similarly, 
frequency of non-intervention under the punishment condition was significantly decreased. These results can also be interpreted in terms of the incentive theory of motivation (Bernstein, 2011). As stated earlier, external incentives appear to have a potent influence on likelihood of third party punishment even when personality differences are taken into account.

Nevertheless, there were significant effects of psychopathy on the frequency of non-intervention. High psychopathy participants were more likely to choose the non-intervention option as compared to low psychopathy participants under the reward condition. In this study, high psychopathy participants did not intervene in the unfair situation at a rate of about $70 \%$ when there were rewards for non-intervention. High psychopathy individuals appear to prioritize personal gain over enforcement of social norms, which is consistent with core features of psychopathy, including egocentricity, shallow emotions, callousness towards others, and lack of empathy (Hare, 1991, 1998, 2003). Previous studies have found a positive relationship between psychopathy and abnormal hypersensitivity to reward (e.g., Masui \& Nomura, 2011; Newman et al., 2005; Osumi et al., 2007). This hypersensitivity to reward could account for why high psychopathy individuals often fail to intervene when a social norm is violated in the present paradigm, although other explanations remain viable.

The present study has a number of limitations. Firstly, we did not examine intervention and non-intervention within the context of long-term human relationships. In the short term, it seems that costly intervention is more irrational in terms of survival value than non-intervention. However, evolutionary accounts explain the purpose and adaptive value of human altruistic behavior in terms of iterated reciprocal relationships. For example, Nowak and Sigmund (1998) argued that the establishment of indirect reciprocity, which is a mechanism for the indirect exchange of helping behavior over a three-way interaction, was an influential factor in the development of altruistic behavior in human society. Furthermore, evolutionary simulations of indirect reciprocity suggest that cooperation can be established through discriminatory strategies, which involve behaving altruistically only toward altruistic others (Nowak \& Sigmund, 1998). Further research is necessary to confirm whether the present findings pertain to long-term human relationships and to investigate the links between the evolutionary meaning of altruistic behavior, external incentives, and psychopathy. Secondly, this study used a small sample that was limited to university students. The small and limited sample size restricts the generalizability of findings on the relationship between altruistic behavior and psychopathy. Moreover, the limited sample size makes it unclear if the present findings would be valid in clinical settings and in clinical populations. A previous study has demonstrated that LSRP scores were moderately correlated with PCL-R scores among women (Brinkley, Schmitt, Smith, \& Newman, 2001). Thirdly, this study only used a self-report measure of psychopathy. Further investigations that include a larger and a more diverse sample and interview-based measures are required to expand our understanding of the ultimate causes of psychopathy and develop treatment methods. Finally, the present study did not clarify the effects of the degree of external incentives offered on the frequency of non-intervention. Masui and Nomura (2011) found that a greater degree of external incentive made it less likely that high psychopathy individuals would inhibit their behavior, as compared to a less external incentive. Various degrees of external inventive could also be studied in the context of intervention or non-intervention when social norms are violated.

Despite these limitations, our findings do help to clarify important links between external incentives, psychopathy, and intervention in unfair social situations, contributing to our understanding of human altruistic behavior, observance of a social norm, and cultivation and continuation of reciprocal human relationships from an evolutionary perspective.

\section{Declaration of Conflicting Interests}

The author(s) declare no potential conflicts of interest with respect to the research, authorship, and/or publication of this article.

\section{References}

Belmore, M. F., \& Quinsey, V. L. (1994). Correlates of psychopathy in a noninstitutional sample. Journal of Interpersonal Violence, 9, 339-349. http://dx.doi.org/10.1177/088626094009003004

Bernstein, D. A. (2011). Essentials of psychology. Belmont, CA: Wadsworth.

Birbaumer, N., Veit, R., Lotze, M., Erb, M., Hermann, C., ... Grodd, W. (2005). Deficient fear conditioning in psychopathy: A functional magnetic resonance imaging study. Archives of General Psychiatry, 62, 799-805. http://dx.doi.org/10.1001/archpsyc.62.7.799 
Brinkley, C. A., Schmitt, W. A., Smith, S. S., \& Newman, J. P. (2001). Construct validation of a self-report psychopathy checklist-revised. Personality and Individual Differences, 31, 1021-1038. http://dx.doi.org/10.1016/S0191-8869(00)00178-1

De Quervain, D. J. F., Fischbacher, U., Treyer, V., Schellhammer, M., Schnyder, U., ... Buck, A. (2004). The neural basis of altruistic punishment. Science, 305, 1254-1258. http://dx.doi.org/10.1126/science.1100735

Edens, J. F., Marcus, D. K., Lilienfeld, S. O., \& Poythress, N. G. (2006). Psychopathic, not psychopaths: Taxometric evidence for the dimensional structure of psychopathy. Journal of Abnormal Psychology, 115, 131-144. http://dx.doi.org/10.1037/0021-843X.115.1.131

Fehr, E., \& Fischbacher, U. (2004a). Third-party punishment and social norms. Evolution and Human Behavior, 25, 63-87. http://dx.doi.org/10.1016/S1090-5138(04)00005-4

Fehr, E., \& Fischbacher, U. (2004b). Social norms and human cooperation. TRENDS in Cognitive Sciences, 8, 185-190. http://dx.doi.org/10.1016/j.tics.2004.02.007

Fehr, E., \& Gächter, S. (2002). Altruistic punishment in humans. Nature, 415, 137-140. http://dx.doi.org/10.1038/415137a

Flor, H., Birbaumer, N., Hermann, C., Ziegler, S., \& Patrick, C. J. (2002). Aversive Pavlovian conditioning in psychopaths: Peripheral and central correlates. Psychophysiology, 39, 505-518. http://dx.doi.org/10.1111/1469-8986.3940505

Guay, J. P., Ruscio, J., Knight, R. A., \& Hare, R. D. (2007). A taxometric analysis of the latent structure of psychopathy: Evidence for dimensionality. Journal of Abnormal Psychology, 116, 701-716. http://dx.doi.org/10.3410/f.1112039.568008

Hare, R. D. (1991). The Hare Psychopathy Checklist-Revised. Toronto, ON: Multi-Health Systems.

Hare, R. D. (1998). Psychopaths and their nature: Implications for the mental health and criminal justice systems. In T. Millon, E. Simonsen, M. Biket-Smith, \& R. D. Davis (Eds.), Psychopathy: Antisocial, criminal and violent behavior (pp. 188-212). New York: Guilford Press.

Hare, R. D. (2003). The Hare Psychopathy Checklist-Revised (2nd ed.). Toronto, ON: Multi-Health Systems.

Ishikawa, S. S., Raine, A., Lencz, T., Bihrle, S., \& Lacasse, L. (2001). Autonomic stress reactivity and executive functions in successful and unsuccessful criminal psychopaths from the community. Journal of Abnormal Psychology, 110, 423-432. http://dx.doi.org/10.1037//0021-843X.I10.3.423

Koenigs, M., Krepke, M., \& Newman, J. P. (2010). Economic decision-making in psychopathy: A comparison with ventromedial prefrontal lesion patients. Neuropsychologia, 48, 2198-2204. http://dx.doi.org/10.1016/j.neuropsychologia.2010.04.012

Leibbrandt, A., \& López-Pérez, R. (2011). The dark side of altruistic third-party punishment. Journal of Conflict Resolution, 55, 761-784. http://dx.doi.org/10.1177/0022002711408010

Levenson, M. R., Kiehl, K. A., \& Fitzpatrick, C. M. (1995). Assessing psychopathic attributes in noninstitutionalized population. Journal of Personality and Social Psychology, 68, 151-158. http://dx.doi.org/10.1037/0022-3514.68.1.151

Levenson, G. K., Patrick, C. J., Bradley, M. M., \& Lang, P. J. (2000). The psychopaths as observer: Emotion and attention in picture processing. Journal of Abnormal Psychology, 109, 373-385. http://dx.doi.org/10.1037//0021-843X.109J.373

Marcus, D. K., John, S. L., \& Edens, J. F. (2004). A taxometric analysis of psychopathic personality. Journal of Abnormal Psychology, 113, 626-635. http://dx.doi.org/10.1037/0021-843X.113.4.626

Masui, K., Iriguchi, S., Nomura, M., \& Ura, M. (2012). Amount of altruistic punishment accounts for subsequent emotional gratification in participants with primary psychopathy. Personality and Individual Differences, 51, 823-828. http://dx.doi.org/10.1016/j.paid.2011.07.006

Masui, K., \& Nomura, M. (2011). The effects of reward and punishment on response inhibition in non-clinical $\begin{array}{lllll}\text { psychopathy. Personality and Individual Differences, } & \text { 50, }\end{array}$ http://dx.doi.org/10.1016/j.paid.2010.08.024

Newman, J. P., MacCoon, D. G., Vaughn, L. J., \& Sadeh, N. (2005). Validating a distinction between primary and secondary psychopathy with measures of Gray's BIS and BAS constructs. Journal of Abnormal Psychology, 114, 319-323. http://dx.doi.org/10.1037/0021-843X.114.2.319 
Nowak, M. A., \& Sigmund, K. (1998). Evolution of indirect reciprocity by image scoring. Nature, 393, 573-577. http://dx.doi.org/10.1038/31225

Osumi, T., Kanayama, N., Sugiura, Y., \& Ohira, H. (2007). Validation of the Japanese Primary and Secondary Psychopathy Scales. The Japanese Journal of Personality, 16, 117-120. http://dx.doi.org/10.2132/personality.16.117

Rilling, J. K., Glenn, A. L., Jairam, M. R., Pagnoni, G., Goldsmith, D. R., ... Lilienfeld, S. O. (2007). Neural correlates of social cooperation and non-cooperation as a function of psychopathy. Biological Psychiatry, 61, 1260-1271. http://dx.doi.org/10.1016/j.biopsych.2006.07.021

Skinner, B. F. (1938). The Behavior of Organisms: An Experimental Analysis. Cambridge, Massachusetts: B.F. Skinner Foundation.

Sugiura, Y., \& Sato, A. (2005). Validation of the Japanese version of the Primary and Secondary Psychopathy Scale. Poster session presented at the 69th meeting of the Japanese Psychological Association, Tokyo, Japan.

\section{Notes}

Note 1. We excluded amounts of non-intervention from the first ANOVA because these amounts were zero at all times.

\section{Copyrights}

Copyright for this article is retained by the author(s), with first publication rights granted to the journal.

This is an open-access article distributed under the terms and conditions of the Creative Commons Attribution license (http://creativecommons.org/licenses/by/3.0/). 